\title{
GARANTIAS EM SERVIÇOS: DA PROMESSA À RECUPERAÇÃO
}

\author{
Juliana Damian Nunes \\ Judamian3@hotmail.com \\ Universidade do Estado de Santa Catarina - Florianópolis, SC/Brasil \\ Tiago Savi Mondo \\ tiagomondo@gmail.com \\ Complexo de Ensino Superior de Santa Catarina - Florianópolis, SC/Brasil \\ Jane Iara Pereira da Costa \\ Costajane@udesc.br \\ Universidade do Estado de Santa Catarina - Florianópolis, SC/Brasil
}

\begin{abstract}
Recebido em 17/11/2009
Aprovado em 11/04/2011

Disponibilizado em 01/12/2011

Avaliado pelo sistema double blind review

Revista Eletrônica de Administração

Editor: Luís Felipe Nascimento

ISSN 1413-2311 (versão on-line)

Editada pela Escola de Administração da Universidade Federal do Rio Grande do Sul.

Periodicidade: Quadrimestral
\end{abstract}

Sistema requerido: Adobe Acrobat Reader.

\section{RESUMO}

A garantia de serviços é um tema pouco explorado nas publicações científicas, sendo que grande parte do que está disponível como conhecimento gerado a partir de investigações empírico-científicas é relacionado com a qualidade e satisfação dos clientes de serviços e não com o processo de garantia propriamente dito. Assim, o objetivo desta pesquisa é verificar a importância atribuída por clientes do município de Florianópolis às garantias oferecidas por organizações de serviços. A pesquisa se caracteriza por ser exploratória de caráter quantitativo e do tipo survey. A amostra foi composta por 400 consumidores da cidade, sendo o instrumento de coleta de dados um questionário estruturado e não disfarçado. Foi utilizada estatística descritiva com aplicação de cross-tables com testes de qui-quadrado.Os principais resultados mostram o fato de que vários clientes consideram decisiva a garantia na hora de adquirir um serviço, bem como o reconhecimento da importância da postura da empresa diante de uma falha no serviço. Conclui-se com o estudo que a garantia exerce papel fundamental na prestação de serviços e que os consumidores a consideram um diferencial competitivo.

Palavras-chave: Serviços; Marketing de Serviços; Garantias em serviços; Percepção de consumidores. 
Garantias em serviços: da promessa à recuperação

\title{
WARRANTIES IN SERVICES: FROM PROMISE TO RECOVERY
}

\begin{abstract}
The security service is a relatively unexplored subject in scientific publications, and much of what is available as knowledge generated from empirical scientific research is related to quality and customer satisfaction of services and not with the process of ensuring proper said. The objective of this research is to verify the importance attached by clients from the Florianópolis the guarantees offered by service organizations. The research is characterized as exploratory in nature and quantitative survey-type. The sample consisted of 400 consumers in the city, being the instrument of data collection a structured, undisguised. Descriptive statistics was used with the application of cross-tables with chi-quadrado.Os main results show the fact that many customers consider critical to ensure that your purchase of service as well as recognition of the importance of the company's position before a service failure. It concludes with the study that the security has a primary role in providing services and that consumers consider it a competitive edge.
\end{abstract}

Keywords: Services, Marketing, Service Guarantees in services, Perception of consumers.

\section{GARANTÍA EN LOS SERVICIOS: LA PROMESA PARA LA RECUPERACIÓN}

\section{RESUMÉN}

La seguridad del serviço es un tema poco explorado en las publicaciones científicas, y gran parte de lo que está disponible como el conocimiento generado por la investigación científica empírica tiene que ver con la calidad y satisfacción de los clientes de los servicios y no con el proceso de garantizar la adecuada , dijo. Así, el objetivo de esta investigación es examinar la importancia atribuida por los clientes en Florianópolis las garantías ofrecidas por las organizaciones de servicios. La investigación se caracteriza por el estudio exploratorio de carácter cuantitativo, de tipo. La muestra consistió en 400 consumidores de la ciudad, y el instrumento de recolección de datos y una no disimulada estructurado. Se utilizó estadística descriptiva con la aplicación de tablas cruzadas con los resultados principales de Chiquadrado.Os muestran el hecho de que muchos clientes consideran fundamentales para garantizar la compra de un servicio, así como el reconocimiento de la importancia de la posición de la empresa antes una deficiencia en el servicio. Concluye con la seguridad de que el estudio tiene un papel primordial en la prestación de servicios y que los consumidores lo consideran una ventaja competitiva.

Palabras clave: Servicios, Servicios de Marketing; Garantías en los servicios, y la percepción de los consumidores.

\section{INTRODUÇÃO}

A pesquisa mercadológica é uma fonte de informações aos gestores de todo e qualquer 
Juliana Damian Nunes, Tiago Savi Mondo \& Jane Iara Pereira da Costa

tipo de organização. Serve tanto para futuros empreendedores que precisam conhecer o mercado no qual irão atuar, quanto para empresários que já estão trabalhando e precisam conhecer com maiores detalhes seus concorrentes, segmento-alvo, ou ainda, as opiniões e idéias de seus funcionários. A presente pesquisa trata do setor de serviços, tendo seu foco direcionado às garantias ofertadas por esse setor, através da percepção dos consumidores da cidade de Florianópolis (SC).

O setor de serviços representa o maior crescimento visto atualmente e já é responsável pela maior parte do PIB brasileiro (65,8\%), conforme dados do IBGE (2008). Apesar de sua importância, no segmento de serviços não existem muitas publicações e pesquisas. Grande parte do que está disponível como conhecimento gerado com base em investigações empíricocientíficas, relaciona-se com qualidade e com a satisfação dos clientes de serviços.

Devido a essa lacuna, torna-se necessário ampliar o conhecimento a respeito da gestão de serviços, mais especificamente sobre as percepções das garantias ofertadas nessa área. Isso, porque a maior parte das publicações referentes à garantia não são abordagens específicas de serviços, mas sim, tratam do assunto relacionando-o a produtos tangíveis.

Devido às peculiaridades dos serviços, uma abordagem direcionada a esse setor em específico, com relação à garantia, faz-se necessária.

Analisando a promessa e o cumprimento da garantia dada pelos fornecedores de serviços aos seus clientes, quando do fechamento do negócio, este artigo pretendeu responder à seguinte pergunta de pesquisa: Qual a importância que clientes atribuem às garantias asseguradas quando da negociação, contratação e aquisição de serviços? Assim, o objetivo do presente artigo é verificar a importância atribuída por clientes às garantias oferecidas por organizações de serviços.

O artigo está estruturado da seguinte forma: A primeira seção introduz o artigo, enquanto que na segunda seção aborda-se teoricamente o assunto de garantias no contexto da prestação de serviços. Na terceira seção são apresentados os aspectos metodológicos que permeiam a presente pesquisa e, na quarta seção, inicia-se a apresentação e discussão a respeito dos resultados obtidos. Por fim, a sexta seção traz as conclusões e considerações finais.

\section{GARANTIAS E O SETOR DE SERVIÇOS}

Nesta seção, aborda-se o tema das garantias tendo como foco o setor de serviços e 
Garantias em serviços: da promessa à recuperação

destaca-se este segmento cuja importância na economia mundial vem crescendo nas últimas décadas de maneira expressiva. Conforme apontam Zeithaml e Bitner (2003), em 1996 o setor de serviços representava $79 \%$ de todos os empregos e, pelo menos, $76 \%$ do Produto Interno Bruto - PIB - dos Estados Unidos.

O Brasil também acompanha essa mesma tendência de crescimento do setor de serviços, apesar de não estar tão próximo das estatísticas dos países mais desenvolvidos. Segundo o IBGE (2008), de 2005 a 2006, houve ganho de participação dos serviços no valor adicionado bruto da economia brasileira, passando de $65,0 \%$ para $65,8 \%$ no período.

Apesar de não ter crescido em grandes proporções, esse percentual continua sendo de alta relevância para a economia do país, já que representa mais da metade de toda riqueza gerada no ano de 2007.

Na cidade de Florianópolis, locus dessa pesquisa, existe um percentual muito maior dos serviços na economia, representando $87,7 \%$ do PIB municipal no ano de 2005, enquanto esse setor representou apenas 65\% do PIB do país no mesmo período (IBGE, 2008). Esse número pode ser explicado pelo fato de Florianópolis ser uma cidade turística e de base tecnológica, sem grandes indústrias e com uma agropecuária pouco expressiva. Logo, é notável a importância do setor de serviços tanto para o país, como para o município estudado.

Rocha e Silva (2006) argumentam que devido à importância econômica do setor, o interesse pelo estudo dessa área aumentou significativamente nos últimos vinte anos. Os autores ainda acrescentam como fator determinante pelo interesse no tema, a redução das possibilidades de diferenciação de produtos com o amadurecimento dos mercados. Dessa forma, os serviços surgem como mais uma opção para as empresas no desenvolvimento de suas vantagens competitivas.

No entanto, é necessário levar em consideração a importância da qualidade na prestação de serviços. O conceito de qualidade nas organizações surgiu primeiramente para empresas de produtos e, somente algum tempo depois, essa preocupação transferiu-se também para empresas de serviços.

A evolução da qualidade é explicada por Oliveira (2006) ao dividi-la em três grandes fases: era da inspeção, era do controle estatístico e era da qualidade total. A era contemporânea da qualidade total mudou o foco do produto para o cliente. A preocupação agora é satisfazer as necessidades e expectativas do cliente e toda a organização é responsável por isso. Dá-se ênfase na prevenção de defeitos, e não mais na sua identificação. Além disso, 
Juliana Damian Nunes, Tiago Savi Mondo \& Jane Iara Pereira da Costa

um passo muito importante foi dado no desenvolvimento das organizações: a qualidade passou a ser assegurada ao cliente. No entanto, para assegurar qualidade, é preciso ter um bom conhecimento a seu respeito e de suas implicações.

Ao tratar da qualidade, Paladini (2000), atenta para a necessidade de focalizá-la na perspectiva do consumidor, já que o produto ou serviço é destinado a ele. Importante ressaltar que, diferentemente do que acontece com produtos, os serviços não podem ser verificados e testados antes de sua entrega ao cliente, sendo mais complexo garantir a sua qualidade, o que os torna mais sujeitos a falhas. Essas falhas podem ocorrer por diversos motivos: não execução do serviço no tempo previsto, desatenção dos funcionários, execução incorreta do serviço, entre outras situações.

Para Hoffman e Bateson (2003, p.387), as falhas de serviço podem ser agrupadas em três categorias principais: “(1) respostas às falhas no sistema de prestação de serviço; (2) respostas às necessidades e pedidos do cliente; e (3) ações do funcionário não induzidas e não solicitadas". Para os autores, as falhas do sistema da prestação de serviço estão diretamente ligadas ao núcleo de serviço da empresa. Elas podem decorrer de serviços indisponíveis, de serviços extraordinariamente lentos ou, ainda, de outras falhas de serviços básicos.

As falhas, na visão de Zeithaml e Bitner (2006), geram sentimentos e reações negativas dos clientes, podendo levá-los a contar essas más experiências a outros clientes ou, até mesmo, levá-los a reclamar do serviço em órgãos de defesa do consumidor. Dessa forma, as falhas geram insatisfações, e a satisfação é, na maioria dos casos, o fator principal que leva à lucratividade nas empresas (KOTLER; KELLER, 2006; CORRÊA; CAON, 2002; LOVELOCK; WIRTZ, 2006). Por isso, as falhas são tão preocupantes e requerem uma atenção especial da organização.

Com a intenção de solucionar esse problema, surge a recuperação de serviços que "compreende as ações tomadas por uma empresa em resposta a uma falha de serviço" (ZEITHAML; BITNER, 2006, p.161). Compreende, portanto, as ações e estratégias de uma organização para gerenciar as falhas ocorridas em seus processos.

"O modo como uma empresa gerencia a recuperação de serviço cria uma plataforma para fortalecer ou enfraquecer os relacionamentos com clientes" (GRONROOS, 2003, p.146). Caso o cliente perceba que a empresa está empenhada em solucionar o seu problema ou está tentando satisfazê-lo da melhor forma, sua percepção com relação a ela será positiva. No entanto, se não for dada a devida atenção ao seu problema ou ele não for bem atendido, a 
Garantias em serviços: da promessa à recuperação

empresa será má vista pelo cliente.

Assim, estratégias para a recuperação de um serviço são citadas por alguns autores. Lovelock e Wirtz (2006) discutem três princípios para desenvolver procedimentos eficazes na recuperação: facilitar o retorno para o cliente, habilitar recuperação eficaz de serviço e determinar níveis de compensação adequados.

O primeiro princípio é referente à tentativa de vencer a relutância dos clientes insatisfeitos em reclamar das falhas ocorridas. Kotler e Keller (2006) apresentam um dado instigante sobre o tema. Argumentam que apenas $4 \%$ dos clientes insatisfeitos costumam reclamar; os demais, muitas vezes, apenas deixam de comprar. Por isso, é tão importante facilitar a reclamação do cliente.

O segundo princípio para a recuperação eficaz de um serviço está relacionado à forma como essa recuperação será dada. Não basta se desculpar com o cliente, mostrando-se solícito quando é efetivada a reclamação. Torna-se preciso ser proativo, de preferência identificando a insatisfação antes que o cliente efetivamente reclame. Também é preciso planejar os procedimentos de recuperação e que exista um treinamento com funcionários para que estes possam adquirir habilidades perante o cliente para a recuperação do serviço. Finalmente, é preciso dar certa autonomia para os funcionários a fim de que estes se sintam capazes de resolver problemas fora do comum. (LOVELOCK; WIRTZ, 2006)

$\mathrm{O}$ último princípio citado pelos autores diz respeito à compensação adequada pela falha ocorrida. Para tanto, é preciso ponderar o posicionamento da empresa no mercado (quanto maior for a sua excelência em serviços, maior o esforço para recuperar uma falha); quão grave foi a falha (quanto maior a falha, mais alta será a recompensa); e, quem é o cliente afetado (clientes importantes para a empresa valem um grande esforço para mantê-los satisfeitos).

\subsection{As garantias em serviços}

A compensação ou recuperação de falhas está diretamente relacionada com as garantias de serviços, tópico a ser discutido neste item. No entanto, garantir a boa qualidade de um produto parece ser muito mais fácil do que garantir a qualidade de um serviço, já que o produto pode ser testado antes de ser entregue ao cliente. Porém, algumas empresas em que parece ser impossível garantir o serviço, têm mostrado que há possibilidades de oferecer garantias a seus clientes, como é o caso dos hotéis Hampton Inn citado por Lovelock e Wirtz 
Juliana Damian Nunes, Tiago Savi Mondo \& Jane Iara Pereira da Costa

(2006) em que é garantida satisfação de $100 \%$ do cliente, caso contrário, não é preciso pagar a hospedagem.

Por ser uma forma de recuperação, a garantia é, portanto, de extrema relevância na prestação de um serviço, já que assegura ao cliente a sua execução de forma satisfatória. Caso contrário, a empresa se compromete a providenciar meios para recompensar o cliente.

A garantia, segundo Johnston e Clark (2002, p.458) é a "promessa de recompensar um cliente pela prestação do serviço abaixo de um nível definido".

Quanto aos tipos de garantia, Lovelock e Wirtz (2006, p.335) apresentam os seguintes:

- Garantia específica para um único atributo: um atributo do serviço é coberto pela garantia;

- Garantia específica para vários atributos: alguns atributos importantes do serviço são cobertos pela garantia;

- Garantia de satisfação total: todos os aspectos do serviço são cobertos pela garantia.

- Garantia combinada: todos os aspectos do serviço são cobertos pela promessa de satisfação total da garantia.

Além dessa abordagem, Zeithaml e Bitner (2003) citam como tipos de garantia, as garantias externas e internas. As garantias externas são aquelas oferecidas ao cliente, enquanto que as garantias internas são oferecidas de um departamento da empresa para outro.

Hoffman e Bateson (2003, p.438) apresentam ainda a garantia implícita. "É toda garantia não escrita e não falada, que estabelece um entendimento entre a empresa e seus clientes". Segundo o autor, esse tipo de garantia promove uma espécie de parceria entre cliente e empresa, tendo como base a confiança e o respeito mútuo.

Quanto à eficácia do oferecimento de garantias, Lovelock e Wirtz (2006) explicam que, em alguns casos, é inadequado oferecê-las. Entre esses, uma empresa que já tenha alta reputação no mercado, ou ainda, uma empresa com serviços precários. No primeiro caso, a garantia não agregaria valor para a empresa, e no segundo, a empresa incorreria em altos custos, sendo adequado, portanto, primeiro uma elevação no nível do serviço para somente depois oferecer uma garantia. Nesta linha de pensamento, tem sido sugerido que uma garantia não é a melhor estratégia quando: a qualidade do serviço praticado pela empresa for pobre; uma garantia não combina com a imagem da empresa; a qualidade do serviço é incontrolável; os custos da garantia superam seus benefícios; os clientes têm uma percepção de baixo risco no serviço (LOVELOCK; WIRTZ, 2006; ZEITHAML; BITNER, 2006); ou quando há pouca 
Garantias em serviços: da promessa à recuperação

variabilidade percebida na qualidade do serviço (ZEITHAML; BITNER, 2006).

Dentre os fatores citados, percebe-se uma divergência de opinião entre os autores com relação ao último tópico apresentado. Lovelock e Wirtz (2006), ao contrário de Zeithaml e Bitner (2006), consideram o oferecimento de garantias adequado para empresas que apresentam pouca diferença percebida na qualidade do serviço entre concorrentes ou, quando a maioria dos concorrentes já oferece garantia, sendo assim uma forma de se manter competitivo no mercado. A partir disso, conclui-se que, antes de oferecer uma garantia, é preciso comparar seus benefícios e seus custos para assegurar que os esforços envolvidos nessa ação sejam satisfatórios e compensadores.

Um dos benefícios da garantia, segundo Hoffman e Bateson (2006), é facilitar alguns aspectos da organização, como: reforçar a fidelidade do cliente, ganhar participação de mercado e obrigar a empresa a melhorar sua qualidade geral de serviço. Além disso, pelo fato da garantia assegurar que o serviço será realizado de acordo com o que foi definido anteriormente, obtém-se um outro benefício: a confiança do cliente.

Através da garantia, o cliente ficará seguro de que o serviço será prestado conforme prometido pela empresa. Assim, pode-se dizer que a garantia é um meio de prover confiança ao cliente. Atenta-se, então, para o fato de que a confiabilidade é uma dimensão da qualidade que tem muita importância para os consumidores (BATESON, HOFFMAN; 2001; LOVELOCK, 2001). Com isso, pode-se inferir que a garantia é um fator fundamental para se chegar à qualidade pretendida. E, a partir disso, é possível entender a relevância do oferecimento de garantia na prestação de um serviço.

A garantia é uma forma de recuperação de falhas, e esta, por sua vez, tem como propósito manter e assegurar a qualidade do serviço. A qualidade é um dos fatores responsáveis pela satisfação do cliente, e a satisfação, na maioria das vezes, ocasiona a fidelidade. Por fim, estudos afirmam que a fidelidade do cliente é fonte geradora de lucros, devido às receitas geradas à empresa. Assim, é possível afirmar que a garantia tem como propósito maior gerar lucro para a organização através da satisfação do cliente.

\subsection{Garantia contratual e garantia legal}

Após uma abordagem conceitual e do ponto de vista mercadológico das garantias, cabe apresentar alguns aspectos jurídicos sobre o tema. Para tanto, utilizou-se o Código de Defesa do Consumidor (CDC) como principal instrumento de pesquisa do conteúdo. 
Juliana Damian Nunes, Tiago Savi Mondo \& Jane Iara Pereira da Costa

Normalmente, entende-se por garantia o termo que acompanha o produto ou serviço, fornecido pela empresa, que assegura o bom funcionamento do produto ou serviço adquirido, por um prazo determinado. Essa garantia é, também, comumente veiculada na mídia para promoção da empresa. Porém, para o CDC, este é apenas um tipo de garantia, denominado garantia contratual.

A garantia contratual está prevista no artigo 50 do CDC, e informa o seguinte:

“A garantia contratual é complementar à legal e será conferida mediante termo escrito.

Parágrafo único. O termo de garantia ou equivalente deve ser padronizado e esclarecer, de maneira adequada em que consiste a mesma garantia, bem como a forma, o prazo e o lugar em que pode ser exercitada e os ônus a cargo do consumidor, devendo ser-lhe entregue, devidamente preenchido pelo fornecedor, no ato do fornecimento, acompanhado de manual de instrução, de instalação e uso do produto em linguagem didática, com ilustrações." (LEI Nº 8.078, DE $11 \mathrm{DE}$ SETEMBRO DE 1990.)

Pela análise do artigo 50, obtêm-se, portanto, duas informações. A primeira diz respeito à complementaridade da garantia contratual e legal, sendo, então, necessário o somatório do prazo contratual da garantia com o prazo legal para se chegar à garantia total do produto ou serviço. Assim, se uma empresa de refrigeradores, por exemplo, fornecer um ano de garantia do seu produto, adiciona-se mais noventa dias, conforme especificado na lei, referente à garantia legal, totalizando, então, um ano e noventa dias de garantia do produto.

A segunda informação que se pode retirar do artigo 50 refere-se à necessidade da garantia contratual ser fornecida através de termo escrito ao cliente. Dessa forma, conclui-se que esse tipo de garantia não pode ser concedido verbalmente, ou, caso isso aconteça, o consumidor não terá o direito de cobrar judicialmente por essa garantia.

Por outro lado, existe a garantia legal que independe de termo escrito ou verbal, conforme previsto no artigo 24 do CDC: "A garantia legal de adequação do produto ou serviço independe de termo expresso, vedada a exoneração contratual do fornecedor." (LEI N ${ }^{\circ}$ 8.078, DE 11 DE SETEMBRO DE 1990.)

Caldeira (2005, p.40), explica de forma clara a diferença entre garantia legal e contratual. Primeiramente, a autora elucida o que vem a ser a garantia legal:

“A garantia legal refere-se ao funcionamento adequado e seguro do produto ou serviço, o que significa dizer que todos os produtos e serviços devem funcionar de acordo com o fim ao qual foram destinados. Assim, se o consumidor adquire uma geladeira e esta não 
Garantias em serviços: da promessa à recuperação

funciona ou funciona mal, tem ele o direito de reclamar."

Já por meio da garantia contratual, “o fornecedor atesta que seu produto ou serviço não só está em perfeitas condições de uso, como também que assim o continuará por mais ' $\mathrm{X}$ ' tempo" (CALDEIRA, 2005, p.40).

Cabe ressaltar, então, que a garantia contratual depende da vontade do fornecer em concedê-la. Dessa forma, o prazo da garantia contratual é estabelecido pelo fornecedor de acordo com a sua vontade e conforme descrito no termo escrito entregue ao cliente. Já a garantia legal está prevista em lei, mesmo que o fornecer não a mencione. O prazo dessa garantia é determinado pelo artigo 26 do CDC: “O direito de reclamar pelos vícios aparentes ou de fácil constatação caduca em: I - trinta dias, tratando-se de fornecimento de serviço e de produtos não duráveis; II - noventa dias, tratando-se de fornecimento de serviço e de produtos duráveis”. (LEI Nº 8.078, DE 11 DE SETEMBRO DE 1990.)

Além desses dois tipos de garantias, existe a forma tácita, que consiste em um compromisso verbal do fornecedor que assegura ao cliente a garantia da prestação do serviço. Apesar do cliente não poder recorrer judicialmente através dessa garantia, ela serve como uma afirmação do prestador de que o serviço atenderá as expectativas do cliente. Caso isso não venha a se confirmar, nenhum dano concreto/judicial pode ser creditado à empresa, porém sua credibilidade é afetada.

Evidencia-se então, a importância que o prestador de serviço deve atribuir às promessas. Deve prometer somente aquilo que pode cumprir, para não tirar a sua credibilidade e a confiança do cliente. Do mesmo modo, deve-se prestar muita atenção na publicidade feita pela empresa, já que, de acordo com o artigo 30 do CDC, toda informação veiculada por qualquer meio de comunicação relacionada a produtos e serviços oferecidos pela empresa "obriga o fornecedor que a fizer veicular ou dela se utilizar e integra o contrato que vier a ser celebrado".

\section{METODOLOGIA}

São apresentadas neste tópico as informações relativas à natureza da pesquisa, amostra e o instrumento utilizado para a coleta de dados, bem como o procedimento de coleta de dados e o procedimento de análise com as principais inferências estatísticas. 
Juliana Damian Nunes, Tiago Savi Mondo \& Jane Iara Pereira da Costa

\subsection{Natureza de Pesquisa}

Segundo a taxionomia apresentada por Mattar (1993), esta pesquisa configura-se como quantitativa. Quanto à natureza dos relacionamentos das variáveis estudadas é exploratóriadescritiva e quanto ao objetivo e ao grau em que o problema está centrado, é uma pesquisa conclusiva. A pesquisa assume caráter quantitativo porque quantifica as informações coletadas e as analisa por meio de técnicas estatísticas.

Por se tratar de tema pouco investigado, sobre o qual não existe consolidado muito conhecimento científico, caracteriza-se também esta pesquisa, como exploratória.De acordo com Malhotra (2005), a pesquisa exploratória tem como objetivo proporcionar esclarecimento e compreensão do objeto de estudo.

Assume também a forma descritiva, porque trata de descrever da maneira mais completa possível o elemento garantia, do segmento de serviços, levando o pesquisador a conhecer e interpretar a realidade, buscando analisar variáveis com a realidade.

\subsection{Amostra}

A pesquisa tem como universo todos os clientes de empresas prestadoras de serviços da cidade de Florianópolis. Dessa forma, tem-se um universo desconhecido, considerado infinito. População ou universo "é o grupo inteiro de pessoas sobre quem o pesquisador necessita obter informações" (MCDANIEL e GATES, 2005, p.186).

A amostra de clientes foi definida, de acordo com o critério estabelecido para população infinita. Os parâmetros adotados para o cálculo amostral representam $95 \%$ de confiança e 5\% de erro amostral, resultando em um total de 400 respondentes.

A seleção da amostra caracterizou-se como probabilística simples, em que "cada elemento da população tem uma probabilidade conhecida e igual de ser selecionado" (MALHOTRA, 2006, p. 330).

\subsection{Instrumento de Pesquisa}

As informações dos clientes de empresas prestadoras de serviços foram obtidas mediante instrumento de coleta de dados na forma de questionário estruturado e nãodisfarçado. De acordo com Malhotra (2006), no método de aplicação de questionário estruturado não-disfarçado é elaborado um questionário formal e as perguntas são feitas em uma ordem pré-determinada; assim o processo é também direto. 
Garantias em serviços: da promessa à recuperação

Foi realizado um pré-teste com 20 consumidores de serviços, selecionados aleatoriamente na cidade de Florianópolis.

\subsection{Procedimento de Coleta de Dados}

A coleta de dados foi realizada entre os dias 17 de Maio e 15 de Julho de 2009, sendo realizada, em sua maioria, no centro de Florianópolis. Utilizou-se para tabulação e análise dos dados o programa SPSS $®$ versão 17.0, software específico de dados, a partir do qual foram feitas análises e cruzamentos dos dados coletados. O processamento, tabulação de dados e análise dos dados ocorreram no mês Agosto de 2009.

\subsection{Procedimento de Análise dos Dados}

Após terem sido armazenados, os dados foram organizados de maneira a facilitar o procedimento e as inferências estatísticas. Os procedimentos estatísticos utilizados compreenderam a estatística descritiva, com frequiências, médias e desvios padrões para as variáveis, aplicados isoladamente.

Além disso, foi realizada a aplicação de tabelas de relação (cross-tables), que proporcionaram relacionar diferentes variáveis do estudo para fundamentar as análises. Para validação destas, foram realizados testes de qui-quadrado para as tabelas, com um nível de significância de $\mathrm{p}<0,05$.

\section{APRESENTAÇÃO DOS RESULTADOS}

Com base nos dados coletados, nesta seção, os resultados e análises são apresentados.

\subsection{Caracterização dos Respondentes da Pesquisa}

Dos 400 respondentes da pesquisa, 211 eram homens (52,8\%) e 189 mulheres (47,2\%). Com relação à faixa etária, 75\% estavam dentro da faixa de 19 à 49 anos, sendo os outros $25 \%$ distribuídos até 18 anos e maiores de 50 anos.

No aspecto da escolaridade 170 respondentes (42,5\%) possuiam ensino médio completo, seguidos de 90 graduados no ensino superior (22,5\%) e 43 com nível fundamental $(10,8 \%)$. Os demais possuiam ensino básico e pós-graduação $(24,2 \%)$.

A faixa de renda pessoal foi de $\mathrm{R} \$ 415,00$ à $\mathrm{R} \$ 1245,00$ em 184 casos (46\%), seguidos 
Juliana Damian Nunes, Tiago Savi Mondo \& Jane Iara Pereira da Costa

dos que possuem de $\mathrm{R} \$ 1245,00$ à $\mathrm{R} \$ 2490,00$ (86 casos, 21,5\%), o restante da amostra ficou distribuída em até $\mathrm{R} \$ 415,00$ (8\%) e acima de $\mathrm{R}$ \$ 2490,00 (24,5\%).

\subsection{A Garantia de Serviços}

Algumas questões gerais sobre garantias em serviço foram apresentadas aos respondentes da pesquisa. Quando da utilização da garantia em algum serviço que tenha ocorrido falha, 196 pessoas (49\%) responderam que já utilizaram a garantia de algum serviço e $204(51 \%)$ nunca utilizaram.

No tocante ao questionamento ao prestador de serviço se o mesmo oferece garantia, $265(66,3 \%)$ respondentes disseram sempre perguntar, seguidos por $42(10,5 \%)$ que responderam perguntar as vezes e $41(10,3 \%)$ na maioria das vezes. Os que raramente perguntam e os que nunca perguntam somaram 52 (13\%).

Quando questionados se davam preferência aos prestadores de serviço que ofereciam garantias $293(73,3 \%)$ dos respondentes disseram sim, enquanto, $67(16,8)$ não e $40(10 \%)$ às vezes.

Estas questões mostram que boa parte dos consumidores de serviços da cidade de Florianópolis questionam sobre a garantia dos serviços oferecidos e dão preferência aos prestadores de serviço que a oferecem.

A análise do conteúdo é corroborada quando os consumidores respondem sobre a crença nas garantias oferecidas. Os que acreditam totalmente ou parcialmente somam 338, representando 84,6\% da amostra. Os que não acreditam são 37 (9,3\%) e os que acreditam somente através de contrato escrito somam 25 respondentes $(6 \%)$.

Abordando o aspecto do contrato, foi verificado quais as formas de garantia que o consumidor mais acredita. O contrato, por ser um instrumento legal, somou 285 respostas, a garantia falada 17 e o selo de garantia 98. O selo de garantia normalmente corresponde à garantia de um serviço relacionada à um produto.

As empresas que prestam serviços e utilizam-se de contratos para legitimar a garantia normalmente oferecem uma cópia do mesmo para o cliente solicitante. Contudo, dos 400 participantes da amostra, apenas 139 (34,75\%) admitiram ler o contrato sempre, enquanto 100 respondentes (25\% ) lêem o contrato as vezes e 161 (40,25\% ) lêem raramente ou nunca.

Quando da verificação das iniciativas dos respondentes frente à garantia de serviços, procurou-se questionar também, se os respondentes que já tiveram problema na prestação de 
Garantias em serviços: da promessa à recuperação

serviços e não utilizaram a garantia. Verificou-se que 108 pessoas já tiveram problema e não utilizaram a garantia,

\subsection{Falhas em serviços versus a Garantia do Serviço}

Este tópico apresenta as características dos respondentes no tocante à ocorrência de falha em serviços e a postura dos mesmos e das prestadoras de serviços com relação à temática.

Dentre os 400 entrevistados, $231(57,8 \%)$ já tiveram problemas com serviços, sendo que $169(42,3 \%)$ responderam que nunca tiveram.

Assim, as análises da pesquisa referente à garantia de serviços focam os que já tiveram algum problema na aquisição de algum serviço. Para conhecer os principais problemas foi solicitado que os entrevistados citassem o ocorrido. Estes problemas, são apresentados na tabela 1.

Tabela 1 - Serviços com os quais já teve problema

\begin{tabular}{ccc}
\hline & Frequência & Percentual \\
\hline Conserto de eletrodomésticos & 83 & 27,39 \\
Oficina mecânica & 65 & 21,45 \\
Manutenção de equipamento de informática & 59 & 19,47 \\
Conserto de equipamentos. eletrônicos & 41 & 13,53 \\
Reparos e reformas de roupas & 18 & 5,94 \\
Conserto de calçados & 16 & 5,28 \\
Lavanderia & 11 & 3,63 \\
Agências de viagens & 6 & 1,98 \\
Outro & 4 & 1,32 \\
Total & 303 & 100,00 \\
\hline
\end{tabular}

Fonte: dados primários/2009.

Percebe-se nesta tabela que a maior incidência de falhas em serviços prestados aos clientes com falhas, foi constatada no conserto de eletromésticos $(27,39 \%)$, seguido pelos serviços mecânicos( $21,45 \%)$.

Verificou-se um índice de 1,33 falhas em serviço por respondente que já teve falha em serviço( $n=231)$.

Dentre os 231 respondentes que responderam que já tiveram algum serviço com falha, 196 (84,84\%) deles usufruiram da garantia do serviço.

Para uma melhor análise dos serviços que falharam, foi solicitado aos respondentes que constataram falhas, que escolhessem o segmento de atividade econômica da ocorrência 
Juliana Damian Nunes, Tiago Savi Mondo \& Jane Iara Pereira da Costa

mais recente de falha e de garantia. A Tabela 2 apresenta os dados obtidos.

Tabela 2 - Perfil da Falha

\begin{tabular}{cccc}
\hline Segmento da Falha & Frequency & Percent & Cumulative Percent \\
\hline Conserto de eletrodomésticos & 53 & 27,04 & 27,04 \\
Manutenção de equip. informática & 44 & 22,45 & 49,49 \\
Oficina mecânica & 43 & 21,94 & 71,43 \\
Conserto de equip. eletrônicos & 25 & 12,76 & 84,18 \\
Reparos e reformas de roupas & 11 & 5,61 & 89,80 \\
Lavanderia & 7 & 3,57 & 93,37 \\
Conserto de calçados & 6 & 3,06 & 96,43 \\
Outro & 4 & 2,04 & 98,47 \\
Agências de viagens & 3 & 1,53 & 100,00 \\
Total & 196 & 100 & \\
\hline
\end{tabular}

Fonte : dados primários/2009.

Os segmentos de destaque correspondem aos apresentados anteriormente : conserto de eletrodomésticos, manuntenção de equipamentos de informática, mecânicos e equipamentos eletrônicos.

Nos 196 casos de ocorrência de garantia, 154 empresas ou prestadores de serviço autônomos informaram ao cliente que forneciam garantia no serviço e 42 não prestaram nenhuma informação.

Com relação ao tipo de garantia ofertado, a predominância da re-execução do serviço em caso de falha foi evidente (175), seguidos de devolução do dinheiro (16) e crédito em outro serviço (5).

Os clientes também responderam sobre o atendimento dos prestadores de serviço quando a solicitação de garantia foi feita.O Gráfico 1 retrata estes dados. 
Garantias em serviços: da promessa à recuperação

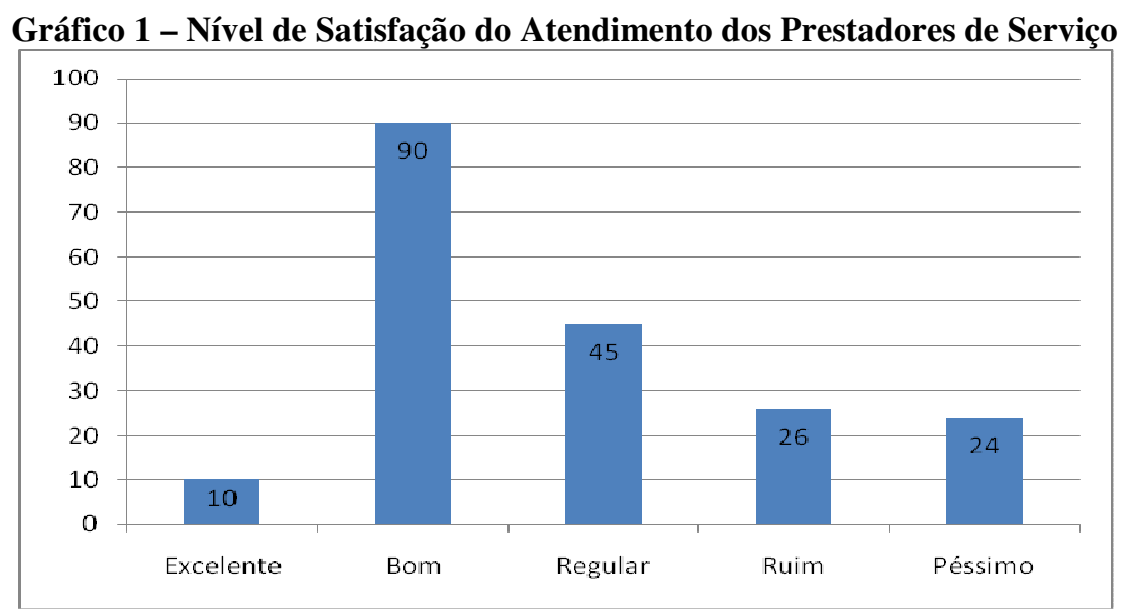

Fonte : dados primários/2009.

Percebe-se que os clientes apresentam satisfação de nível BOM $(45,9 \%)$ quando procuram os prestadores de serviços para atender às suas demandas por garantias.

Foi possível contatar, que mesmo tendo sido o atendimento pós-falha avaliado como bom ou ótimo, o cliente normalmente tem algum receio quanto o serviço e isso reflete na sua satisfação. Os clientes que tiveram falhas e utilizaram a garantia do serviço mostraram-se divididos, $84(42,85 \%)$ responderam que ficaram satisfeitos ou muito satisfeitos e 86 respondentes $(43,87 \%)$ ficaram insatisfeitos ou muito insatisfeitos, tendo ainda 26 pessoas que ficaram regularmente satisfeitas. Pode-se analisar a partir disso que a satisfação depende muito do atendimento e da qualidade do serviço prestado e não somente da garantia. Outras variáveis influenciam na satisfação do cliente. O dado que corrobora a análise é o de retorno ao serviço, 104 pessoas $(53,06 \%)$ não retornariam ao prestador de serviço de maneira alguma, sendo que $73(37,24 \%)$ retornariam, 10 talvez retornariam e 9 somente se fosse opção única.

Para finalizar, foi questionado aos clientes que deixaram de utilizar a garantia, mesmo com a falha do serviço, qual o motivo pelo qual tiveram essa postura. $\mathrm{O}$ valor pequeno do serviço, a distância do local de reclamação, a falta de tempo e o desconforto em solicitar a garantia foram as causas citadas pelos clientes.

Assim, conclui-se que a garantia do serviço é importante para o consumidor, que deve ser planejada pelo gestor e prestador de serviços para ser efetiva quando da ocorrência de falha e que outras variáveis como o atendimento, o contrato e a qualidade do re-serviço influenciam na satisfação do consumidor. 
Juliana Damian Nunes, Tiago Savi Mondo \& Jane Iara Pereira da Costa

\subsection{Análises relacionais da Garantia de Serviços}

Após a etapa descritiva da pesquisa, buscou-se analisar os resultados através de testes estatísticos, descritivos e inferenciais, na busca de motivos, razões ou relações significativas entre as variáveis levantadas pelo estudo.

\subsubsection{A satisfação do cliente após a garantia}

$\mathrm{Na}$ busca de relacionar a satisfação do cliente com alguns pontos levantados na pesquisa apresenta-se algumas cross-tables e suas análises.

A tabela 3 mostra a relação entre a satisfação do cliente que utilizou a garantia do serviço e o tipo de garantia que o prestador de serviço ofertou.

Tabela 3 - Satisfação versus $O$ que foi ofertado

\begin{tabular}{|c|c|c|c|c|c|c|c|}
\hline & \multicolumn{5}{|c|}{ Você ficou satisfeito(a) com a resolução do problema? } & \multirow[b]{2}{*}{ Total } \\
\hline & & $\begin{array}{c}\text { Muito } \\
\text { satisfeito }\end{array}$ & Satisfeito & $\begin{array}{l}\text { Regularmente } \\
\text { satisfeito }\end{array}$ & Insatisfeito & $\begin{array}{l}\text { Muito } \\
\text { insatisfeito }\end{array}$ & \\
\hline \multirow{4}{*}{$\begin{array}{c}\text { O que foi } \\
\text { ofertado como } \\
\text { garantia? }\end{array}$} & $\begin{array}{c}\text { Fazer o } \\
\text { serviço } \\
\text { novamente }\end{array}$ & 9 & 70 & 20 & 52 & 24 & 175 \\
\hline & $\begin{array}{l}\text { Devolução do } \\
\text { dinheiro }\end{array}$ & 1 & 1 & 1 & 6 & 2 & 11 \\
\hline & $\begin{array}{l}\text { Crédito em } \\
\text { outro serviço }\end{array}$ & 0 & 0 & 2 & 0 & 0 & 2 \\
\hline & Outra. & 0 & 3 & 3 & 1 & 1 & 8 \\
\hline \multicolumn{2}{|c|}{ Total } & 10 & 74 & 26 & 59 & 27 & 196 \\
\hline
\end{tabular}

Percebe-se através da tabela, que existe equilíbrio entre o nível de insatisfação e satisfação dos clientes, demonstrado também na fase descritiva deste estudo, contudo, na análise de conteúdo da Tabela 3, destaca-se, apesar de baixa freqüência, a insatisfação dos clientes quando da devolução de dinheiro como garantia ofertada. Isto denota que o cliente quer o serviço executado e não a possibilidade de receber seu dinheiro de volta. Confirmouse, também, a afirmação de Zeithaml e Bitner (2006), a respeito de falhas em serviço, ao dizer que elas geram sentimentos e reações negativas dos clientes.

Para validar a associação entre as variáveis da tabela, foi realizado o teste de quiquadrado. Com um nível de significância para associação das variáveis de $\mathrm{p}<0,05$, foi 
Garantias em serviços: da promessa à recuperação

verificada a existência de associação, validando a análise.

Tabela 4 - Chi-Square Tests

\begin{tabular}{cccc}
\hline & Valor & df & Significância \\
Qui-quadrado & $23,768^{\mathrm{a}}$ & 12 &, 022 \\
\hline
\end{tabular}

Fonte : dados primários/2009.

O nível de satisfação do cliente após a utilização da garantia foi confrontada também com o tipo de serviço prestado. A tabela 5 demonstra os cruzamentos existentes.

Tabela 5 - Satisfação versus Ocorrência de falha mais recente

\begin{tabular}{|c|c|c|c|c|c|c|c|}
\hline & & \multicolumn{5}{|c|}{ Você ficou satisfeito(a) com a resolução do problema? } & \multirow[b]{2}{*}{ Total } \\
\hline & & $\begin{array}{c}\text { Muito } \\
\text { satisfeito }\end{array}$ & Satisfeito & $\begin{array}{l}\text { Regularmente } \\
\text { satisfeito }\end{array}$ & Insatisfeito & $\begin{array}{c}\text { Muito } \\
\text { insatisfeito }\end{array}$ & \\
\hline \multirow{10}{*}{$\begin{array}{c}\text { Procure } \\
\text { lembrar da } \\
\text { ocorrência mais } \\
\text { recente ou mais } \\
\text { importante em } \\
\text { que você tenha } \\
\text { utilizado a } \\
\text { garantia do } \\
\text { serviço. Sobre } \\
\text { qual irá falar? }\end{array}$} & $\begin{array}{l}\text { Manutenção de } \\
\text { equip. informática }\end{array}$ & 0 & 25 & 5 & 9 & 5 & 44 \\
\hline & $\begin{array}{l}\text { Conserto de } \\
\text { eletrodomésticos }\end{array}$ & 2 & 13 & 7 & 20 & 11 & 53 \\
\hline & $\begin{array}{l}\text { Conserto de equip. } \\
\text { eletrônicos }\end{array}$ & 1 & 9 & 3 & 9 & 3 & 25 \\
\hline & $\begin{array}{c}\text { Reparos e reformas } \\
\text { de roupas }\end{array}$ & 1 & 5 & 2 & 2 & 1 & 11 \\
\hline & Lavanderia & 0 & 0 & 1 & 5 & 1 & 7 \\
\hline & $\begin{array}{l}\text { Conserto de } \\
\text { calçados }\end{array}$ & 0 & 2 & 1 & 3 & 0 & 6 \\
\hline & Oficina mecânica & 6 & 20 & 5 & 8 & 4 & 43 \\
\hline & $\begin{array}{l}\text { Agências de } \\
\text { viagens }\end{array}$ & 0 & 0 & 1 & 0 & 2 & 3 \\
\hline & Outro & 0 & 0 & 1 & 3 & 0 & 4 \\
\hline & Total & 10 & 74 & 26 & 59 & 27 & 196 \\
\hline
\end{tabular}

É possível verificar, através da tabela os serviços com destaque nos níveis de satisfação: manutenção de equipamentos de informática e os serviços de oficina mecânica. Por outro lado, os serviços com maior nível de insatisfação foram o conserto de eletrodomésticos e lavanderia. Os outros serviços se mostraram equilibrados entre o nível de satisfação e insatisfação. 
Juliana Damian Nunes, Tiago Savi Mondo \& Jane Iara Pereira da Costa

Para validação da análise, foi realizado o teste de qui-quadrado. Verificou significância estatística $(\mathrm{p}<0,05)$ para a associação das variáveis do estudo de 0,027 como demonstra a tabela 6.

Tabela 6 - Teste de qui-quadrado

\begin{tabular}{cccc}
\hline & Valor & df & Significância \\
Qui-quadrado & $49,163^{\mathrm{a}}$ & 32 &, 027 \\
\hline
\end{tabular}

Fonte : dados primários/2009.

A satisfação do cliente foi relacionada também com a possibilidade de voltar a comprar o mesmo serviço do mesmo prestador. A tabela 7 mostra a relação das variáveis.

Tabela 7 - Satisfação versus Nova utilização do serviço

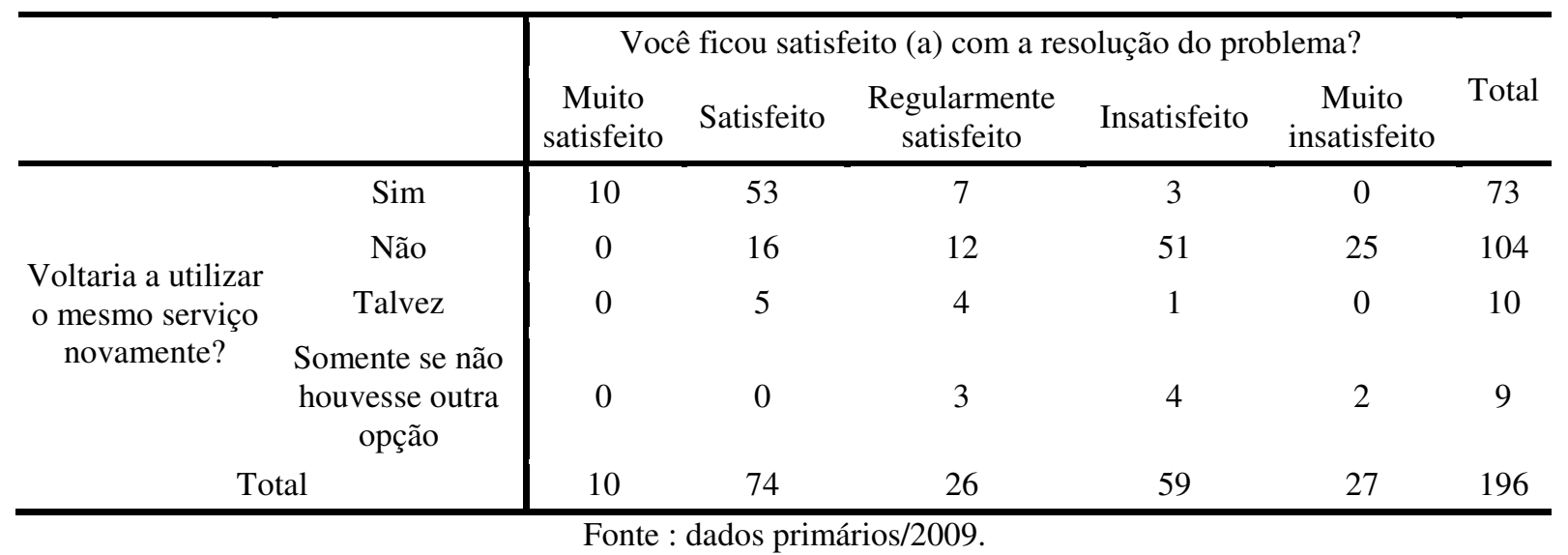

Os resultados apontam que a resolução satisfatória de uma falha em serviço desenvolve a confiabilidade entre o consumidor e a empresa, de tal modo que foi comprovada a relação entre a satisfação com a garantia e a probabilidade de nova utilização do serviço. Cabe, mais uma vez, atentar para o que assinala Gronroos (2003), a respeito da importância da postura da empresa no momento em que a garantia é necessária.

A análise é validada pelo teste de qui-quadrado, representado na tabela 8. 
Garantias em serviços: da promessa à recuperação

Tabela 8 - Teste de qui-quadrado

\begin{tabular}{lccrr}
\hline & Valor & df & Significância \\
Qui-quadrado & $117,589^{\mathrm{a}}$ & & 12 &, 000 \\
\hline
\end{tabular}

Fonte : dados primários/2009.

Em relação aos consumidores que utilizaram a garantia, chama a atenção o percentual de consumidores insatisfeitos com o atendimento, pois, considerando-se as opções regular, ruim e péssimo, totalizaram 48,6\% das avaliações como demonstra a tabela 9é. Se quase metade dos consumidores não ficou satisfeita com o atendimento da empresa no momento da reclamação, é porque existe uma evidente necessidade de revisão por parte das empresas, no modo como atendem a essas reclamações. Talvez as empresas que estão oferecendo garantia em serviços não estão atentando para o que sugerem alguns autores a respeito dos casos em que uma garantia não é a melhor estratégia, por exemplo: quando a qualidade do serviço da empresa é pobre; quando a qualidade do serviço é incontrolável; ou quando os custos da garantia superam seus benefícios, etc. (LOVELOCK; WIRTZ, 2006; ZEITHAML; BITNER, 2006).

Tabela 9 - Satisfação versus Atendimento da Empresa

\begin{tabular}{|c|c|c|c|c|c|c|c|}
\hline & & \multicolumn{6}{|c|}{ Você ficou satisfeito (a) com a resolução do problema? } \\
\hline & & $\begin{array}{l}\text { Muito } \\
\text { satisfeito }\end{array}$ & Satisfeito & $\begin{array}{l}\text { Regularmente } \\
\text { satisfeito }\end{array}$ & Insatisfeito & $\begin{array}{c}\text { Muito } \\
\text { insatisfeito }\end{array}$ & Total \\
\hline \multirow{5}{*}{$\begin{array}{l}\text { O que achou do } \\
\text { atendimento da } \\
\text { empresa quando pediu } \\
\text { que a garantia fosse } \\
\text { utilizada? }\end{array}$} & Excelente & 3 & 7 & 0 & 0 & 0 & 10 \\
\hline & Bom & 7 & 47 & 12 & 18 & 6 & 90 \\
\hline & Regular & 0 & 17 & 9 & 12 & 7 & 45 \\
\hline & Ruim & 0 & 3 & 3 & 17 & 3 & 26 \\
\hline & Péssimo & 0 & 0 & 1 & 12 & 11 & 24 \\
\hline Total & & 10 & 74 & 25 & 59 & 27 & 195 \\
\hline
\end{tabular}

A análise é corroborada pelo qui-quadrado, que mediu associação significante entre as variáveis, apresentado na tabela 10. 
Juliana Damian Nunes, Tiago Savi Mondo \& Jane Iara Pereira da Costa

Tabela 10 - Teste de Qui-quadrado

\begin{tabular}{cccc}
\hline & Valor & df & Significância \\
Qui-quadrado & $86,845^{\mathrm{a}}$ & 16 &, 000 \\
\hline
\end{tabular}

Fonte : dados primários/2009.

Foi realizada a análise em relação ao crédito e descrédito demonstrados pelos clientes com relação à promessa de garantia e a satisfação. A tabela 11 apresenta a relação, logo após é apresentada a Tabela 12, com o teste de qui-quadrado validando a análise.

Tabela 11 - Satisfação versus Crédito do Consumidor perante a oferta de garantia

\begin{tabular}{|c|c|c|c|c|c|c|c|}
\hline & & \multicolumn{5}{|c|}{ Você ficou satisfeito(a) com a resolução do problema? } & \multirow[t]{2}{*}{ Total } \\
\hline & & $\begin{array}{c}\text { Muito } \\
\text { satisfeito }\end{array}$ & Satisfeito & $\begin{array}{l}\text { Regularmente } \\
\text { satisfeito }\end{array}$ & eito & ito & \\
\hline \multirow{4}{*}{$\begin{array}{l}\text { Ao tomar } \\
\text { conhecimento da } \\
\text { garantia de um } \\
\text { serviço, você: }\end{array}$} & Acredita totalmente & 7 & 32 & 8 & 26 & 3 & 76 \\
\hline & $\begin{array}{l}\text { Acredita } \\
\text { parcialmente }\end{array}$ & 3 & 36 & 16 & 26 & 14 & 95 \\
\hline & Não acredita & 0 & 2 & 2 & 4 & 8 & 16 \\
\hline & $\begin{array}{l}\text { Acredita somente se } \\
\text { for por escrito }\end{array}$ & 0 & 4 & 0 & 3 & 2 & 9 \\
\hline Total & & 10 & 74 & 26 & 59 & 27 & 196 \\
\hline
\end{tabular}

Fonte : dados primários/2009.

Não surpreende o descrédito existente em relação à garantia de serviços, tanto que ao adquirir um serviço que possui garantia, apenas 40,8\% dos consumidores acredita totalmente na promessa da garantia ofertada. Ainda em relação à confiança na garantia, confirmou-se que $70 \%$ dos entrevistados que ficaram 'muito satisfeitos' com a resolução do seu problema, acreditam totalmente nas garantias ofertadas pelos prestadores de serviços, enquanto entre os que ficaram "muito insatisfeitos", essa porcentagem cai drasticamente para 11,1\%. Essa afirmação pode ser entendida ao considerar que as emoções influenciam no processo de percepção do cliente sobre o produto ou serviço, ou seja, se a experiência anterior foi ruim, a percepção a respeito da garantia será diretamente influenciada por ela (GAMBLE, et al., 2007). 
Garantias em serviços: da promessa à recuperação

Tabela 12 - Teste de qui-quadrado

\begin{tabular}{lccr}
\hline & Valor & $\mathrm{df}$ & Significância \\
Qui-quadrado & $32,163^{\mathrm{a}}$ & 12 &, 001 \\
\hline
\end{tabular}

Fonte : dados primários/2009.

\subsubsection{Preferência ao prestador de serviço que oferece garantia}

A informação sobre a percepção do cliente em relação às características do serviço pode se tornar conhecimento importante no processo de planejamento da empresa. Buscou-se verificar relações entre as variáveis estudadas e a preferência dos clientes em escolher empresas que ofereçam garantia de serviços.

Foi realizado cruzamento dos dados relacionados com a preferência em escolher estabelecimento que ofereça garantia versus o crédito que o consumidor denota às informações sobre garantia dos prestadores. O resultado é apresentado na Tabela 13.

Tabela 13 - Preferência versus Crédito do consumidor à garantia ofertada

\begin{tabular}{|c|c|c|c|c|c|}
\hline & & \multicolumn{3}{|c|}{$\begin{array}{l}\text { Você costuma dar preferência a um } \\
\text { estabelecimento que ofereça garantia de seus } \\
\text { serviços? }\end{array}$} & \multirow[t]{2}{*}{ Total } \\
\hline & & Sim & Não & Às vezes & \\
\hline \multirow{4}{*}{$\begin{array}{l}\text { Ao tomar conhecimento } \\
\text { da garantia de um serviço, } \\
\text { você: }\end{array}$} & Acredita totalmente & 121 & 26 & 16 & 163 \\
\hline & Acredita parcialmente & 138 & 20 & 17 & 175 \\
\hline & Não acredita & 14 & 16 & 7 & 37 \\
\hline & $\begin{array}{l}\text { Acredita somente se for } \\
\text { por escrito }\end{array}$ & 20 & 5 & 0 & 25 \\
\hline \multicolumn{2}{|c|}{ Total } & 293 & 67 & 40 & 400 \\
\hline
\end{tabular}

Fonte : dados primários/2009.

Percebe-se que, de fato, o consumidor que acredita totalmente ou parcialmente no que o prestador informa dá maior preferência a um estabelecimento que oferece garantia, do que os consumidores que não acreditam ou somente acreditam por meio de contrato. O nível de associação da tabela é mensurado pelo teste de qui-quadrado apresentado na tabela 14 e denota que existe associação significante entre as variáveis, corroborando a análise realizada. 
Juliana Damian Nunes, Tiago Savi Mondo \& Jane Iara Pereira da Costa

Tabela 14 - Teste de qui-quadrado

\begin{tabular}{lccr}
\hline & Valor & df & Significância \\
Qui-quadrado & $31,408^{\text {a }}$ & 6 &, 000 \\
\hline
\end{tabular}

Fonte : dados primários/2009.

Buscou-se analisar se a preferência do consumidor em serviços com garantia era significantemente associada à já utilização ou não da garantia por parte do consumidor. A tabela 15 mostra estas relações, apontando que os que já utilizaram o serviço de garantia, dão uma maior preferência a organizações de serviço que a ofertam, do que os consumidores que ainda não a utilizaram.

Tabela 15 - Preferência versus Utilização de Garantia

\begin{tabular}{|c|c|c|c|c|c|}
\hline & & \multicolumn{3}{|c|}{$\begin{array}{c}\text { Você costuma dar preferência a um estabelecimento } \\
\text { que ofereça garantia de seus serviços? }\end{array}$} & \multirow[t]{2}{*}{ Total } \\
\hline & & Sim & Não & Às vezes & \\
\hline \multirow{2}{*}{$\begin{array}{l}\text { Já utilizou a garantia de } \\
\text { algum destes serviços? }\end{array}$} & Sim & 152 & 20 & 24 & 196 \\
\hline & Não & 141 & 47 & 16 & 204 \\
\hline Total & & 293 & 67 & 40 & 400 \\
\hline
\end{tabular}

Pode-se confirmar a análise a partir do teste de qui-quadrado que demonstrou que existe associação significante entre as variáveis do estudo.

Tabela 16 - Teste qui-quadrado

\begin{tabular}{|c|c|c|c|}
\hline & Valor & $\mathrm{df}$ & Significância \\
\hline Qui-quadrado & $12,739^{\mathrm{a}}$ & 2 &, 002 \\
\hline
\end{tabular}

Fonte : dados primários/2009.

Com o intuito de investigar se a preferência por serviços com garantia estava relacionada de alguma maneira com a postura do consumidor na hora de perguntar sobre as características do serviço buscou-se relacionar nos resultados, a preferência por prestadores que oferecem garantia com a frequência com a qual o consumidor pergunta sobre a garantia. Os dados são demonstrados na Tabela 17.

Novamente, mostrou-se que quanto mais o consumidor se faz parte integrante do 
Garantias em serviços: da promessa à recuperação

serviço, mais ele dá preferência ao serviço que tem bom atendimento.. Nota-se que os consumidores que sempre ou na maioria das vezes perguntam sobre a garantia, preferem de fato, os que a oferecem, com maior frequencia que os consumidores que raramente ou nunca perguntam sobre a garantia. Para validar a análise, houve significância de associação das variáveis como mostra a tabela 18.

Tabela 17 - Preferência versus Frequência de Pergunta sobre garantia

\begin{tabular}{|c|c|c|c|c|c|}
\hline & & \multicolumn{3}{|c|}{$\begin{array}{c}\text { Você costuma dar preferência a um } \\
\text { estabelecimento que ofereça garantia de seus } \\
\text { serviços? }\end{array}$} & \multirow[t]{2}{*}{ Total } \\
\hline & & Sim & Não & Às vezes & \\
\hline \multirow{5}{*}{$\begin{array}{l}\text { Com que frequência você } \\
\text { costuma perguntar se o } \\
\text { serviço tem garantia? }\end{array}$} & Sempre & 222 & 27 & 16 & 265 \\
\hline & Na maioria das vezes & 23 & 4 & 14 & 41 \\
\hline & Às vezes & 22 & 12 & 8 & 42 \\
\hline & Raramente & 12 & 8 & 0 & 20 \\
\hline & Nunca & 14 & 16 & 2 & 32 \\
\hline \multicolumn{2}{|c|}{ Total } & 293 & 67 & 40 & 400 \\
\hline
\end{tabular}

Fonte : dados primários/2009.

Tabela 18 - Teste qui-quadrado

\begin{tabular}{cccc}
\hline & Valor & df & Significância \\
Qui-quadrado & $85,473^{\mathrm{a}}$ & 8 &, 000 \\
\hline
\end{tabular}

Fonte : dados primários/2009.

Assim, percebe-se que a preferência do consumidor por serviços que oferecem garantia é considerada na tomada de decisão do consumidor, e este, quanto mais integrado à prestação de serviço, mais a valoriza.

Outra questão evidenciada pela pesquisa é de que poucos clientes lêem o contrato de garantia, o que pode caracterizar a cultura do consumidor entrevistado, evidenciando às empresas que, se desejam destacar algum aspecto referente ao serviço ou à garantia, não é suficiente citá-lo no contrato de garantia. A resolução de dúvidas de maneira reativa, através do contrato, pode evitar processos ou reclamações judiciais, mas dificilmente evitará a fidelização e satisfação do cliente.

Além disso, o consumidor se torna mais satisfeito, no momento que é bem atendido, que o seu desejo é realizado. Ficou evidente que a devolução de dinheiro e crédito para próximos serviços não resultam na satisfação do cliente, bem como o mau atendimento, entre 
Juliana Damian Nunes, Tiago Savi Mondo \& Jane Iara Pereira da Costa

outras variáveis já apresentadas. Tais dados mostram que o cliente está cada vez mais exigente e que a oferta de garantia se torna imprescindível na prestação de serviços.

\section{CONCLUSÃO}

Este tópico traz a consolidação dos resultados obtidos com esta pesquisa. Ressalta-se a certeza de que quando se fala em prestação de serviços, é imperativo que a qualidade permeie o processo do início ao final. A qualidade é fundamental para diminuir as probabilidades de falhas nas dimensões que podem ser controladas pela empresa. No entanto, por conta de aspectos que não podem ser controlados pela empresa ou por fatores que transcendem essa capacidade, em inúmeros casos ocorrem falhas na prestação de serviços. É diante delas que a garantia de serviços assume grande importância para o consumidor da cidade de Florianópolis (SC). Embora existam pessoas que não acionam garantia por não creditar confiança ou por motivos diversos, a maioria dos consumidores percebe como importante o oferecimento de garantias de serviços, de tal modo que costuma inquirir a esse respeito antes de adquirir o serviço. Essa observação é endossada por Hays e Hill (2006) que em uma pesquisa ofereceram a evidência empírica de que uma garantia do serviço pode ter um efeito positivo e, o mais importante, em longo prazo é significativa na intenção do cliente retornar.

Além disso, é possível perceber, ao entrevistar pessoas que não tiveram boas experiências com garantias de serviço, que o sentimento de frustração pode fazer o cliente não voltar a adquirir o serviço da empresa, comprovando a importância da empresa trabalhar bem a emoção do consumidor, revendo sua postura, que para Gronroos (2003), é determinante diante de uma falha. Aliás, a postura da empresa diante de falhas de serviço foi decisiva para a maioria dos entrevistados, evidenciando a necessidade de estratégias direcionadas a essa questão. Baseando-se nestas questões, a empresa que oferece garantias deve desenvolver políticas e práticas que viabilizem tal serviço de maneira alinhada à sua base de estratégias oorporativas, de modo que exista comprometimento de todos (inclusive da alta gerência) com a garantia e, sobretudo, com a qualidade (HOFFMAN; BATESON, 2006; ZEITHAML; BITNER, 2003; KOTLER; KELLER, 2006).

Outro aspecto importante a ser considerado é a necessidade de comunicação clara junto ao cliente, antes mesmo dele adquirir o serviço, transcendendo a formalidade do manual 
Garantias em serviços: da promessa à recuperação

de garantia (o qual a pesquisa demonstrou que poucos lêem). Essa necessidade existe porque, diante de qualquer problema que possa ocorrer durante ou após a prestação do serviço, estando o cliente bem informado a respeito do que é garantido e como funciona a garantia, o processo tende a não ser traumático e facilitar a reclamação do cliente, que muitas vezes deixa de procurar a garantia (KOTLER; KELLER, 2006).

Finalmente, essa pesquisa pretende constituir-se numa fonte de informações aos gestores de várias organizações, por ter destacado alguns pontos importantes relacionados à garantia de serviços, principalmente às empresas do segmento que oferecem, ou pretendem oferecer, garantia dos serviços.

Como contribuições gerenciais, cita-se a utilização de pesquisas de satisfação e a motivação da empresa para que o cliente possa reclamar sobre as garantias e as possíveis falhas. A partir disso, se torna viável a elaboração de um procedimento padrão no caso da ocorrência de falhas.

A garantia em serviços torna-se, portanto um mecanismo não somente de qualidade na sua prestação, mas de relacionamento com o cliente, busca da excelência e conseqüente satisfação do cliente.

Por último, ressalta-se a importância do prestador de serviço de linha de frente, no atendimento anterior e posterior à prestação. A garantia, as falhas e a própria recuperação configuram-se como temas de capacitações e treinamentos e podem se tornar aliadas da empresa na busca pela satisfação do cliente.

\section{REFERÊNCIAS}

CALDEIRA, Mirella D'Angelo. Aspectos da prescrição e decadência no código de defesa do consumidor. Revista Mestrado em Direito, Osasco, Ano 5, n.5, 2005.

Código de Defesa do Consumidor. Disponível em: <http://www.planalto.gov.br/ccivil_03/leis/18078.htm>. Acesso em 10/04/2009.

CORRÊA, Henrique Luiz; CAON, Mauro. Gestão de serviços: lucratividade por meio de operações e de satisfação dos clientes. São Paulo : Atlas, 2002. 
Juliana Damian Nunes, Tiago Savi Mondo \& Jane Iara Pereira da Costa

DIAS, Sérgio Roberto (Coord.) Gestão de marketing. São Paulo: Saraiva, 2006.

DIRETÓRIO ACADÊMICO DE ADMINISTRAÇÃO E GERÊNCIA DA ESAG. Disponível em: < http://www.daag.org.br/pub/index.pub.php?s=esag > Acesso em: 05/11/2008.

FITZSIMMONS, James A. Administração de serviços: operações, estratégia e tecnologia da informação. 4.ed. Porto alegre: Bookman, 2005.

GAMBLE, P. R.; TAPP, A.; MARSELLA, A.; STONE, M. A revolução do marketing. São Paulo: Editora Futura, 2007.

GONZÁLES, Mário O. A.; AMORIM, Célio G.; RAMOS, Eugênio B. R. A relação entre a satisfação e a fidelidade dos clientes com a lucratividade das empresas. ENEGEP, Florianópolis, 2004.

GRONROOS, Christian. Marketing: gerenciamento e serviços: a competição por serviços na hora da verdade. Rio de Janeiro: Campus, 1995.

GRONROOS, Christian. Marketing: gerenciamento e serviços. $2^{\mathrm{a}}$ ed. Rio de Janeiro: Elsevier, 2003.

HAYS; Julie M.; HILL, Arthur V.. An Extended Longitudinal Study of the

Effects of a Service Guarantee. Production and Operations Management. vol. 15, No. 1, Spring 2006, pp. 117-131

HESKETT, James L., SASSER, W. Earl; HART, Christopher. W. L. Serviços revolucionários: mudando as regras do jogo competitivo na prestação de serviços. São Paulo: Editora Pioneira, 1994.

HOFFMAN, K. Douglas; BATESON, John E. G. Princípios de marketing de serviços: conceitos, estratégias e casos. São Paulo: Pioneira Thomson Learning, 2006.

INSTITUTO BRASILEIRO DE GEOGRAFIA E ESTATÍSTICA. Disponível em: <www.ibge.com.br> Acesso em: 10/12/2008.

JOHNSTON, Robert; CLARK, Graham. Administração de operações de serviço. São 
Garantias em serviços: da promessa à recuperação

Paulo: Atlas, 2002.

KOTLER, Philip; KELLER, Kevin Lane. Administração de marketing. 12.ed. São Paulo: Pearson Prentice Hall, 2006.

LIMA, Miguel et al. Gestão de marketing . 8. ed. rev. e atual. Rio de Janeiro: FGV, 2007.

LOVELOCK, Christopher. Serviços: marketing e gestão. São Paulo: Saraiva, 2001.

LOVELOCK, Christopher; WIRTZ, Jochen. Marketing de serviços: pessoas, tecnologia e resultados. 5 ed. São Paulo: Pearson Prentice Hall, 2006.

MATTAR, Fauze Najib. Pesquisa de marketing: metodologia, planejamento, execução, análise. São Paulo: Atlas, 1993.

MALHOTRA, Naresh K. Pesquisa de marketing: uma orientação aplicada . 3.ed. Porto Alegre: Bookman, 2001.

, Naresh K. Pesquisa de marketing: uma orientação aplicada. 4. ed. Porto Alegre: Bookman, 2006.

MCDANIEL, Carl; GATES, Roger. Fundamentos de pesquisa de marketing. $4^{\mathrm{a}}$ ed. Rio de Janeiro: LTC, 2005.

MINISTÉRIO DO DESENVOLVIMENTO, INDÚSTRIA E COMÉRCIO EXTERIOR. Disponível em: <http://desenvolvimento.gov.br/arquivos/dwnl_1196967724.pdf> Acesso em: 30/10/2008.

MINISTÉRIO DO PLANEJAMENTO, ORÇAMENTO E GESTÃO. Disponível em: $<$ http://www.cnae.ibge.gov.br/estrutura.asp?TabelaBusca=CNAE_200@CNAE-

SUBCLASSES\%202.0> Acesso em: 30/10/2008.

OLIVEIRA, O. J. Gestão da qualidade: tópicos avançados. São Paulo: Pioneira Thomson Learning, 2006.

PALADINI, Edson P. Gestão da qualidade: teoria e prática. São Paulo: Atlas, 2000.

PARASURAMAN, A.; ZEITHAML, Valerie A.; BERRY, Leonard L. Um modelo conceitual 
de qualidade de serviço e suas implicações para a pesquisa no futuro. Revista de Administração de Empresas - RAE, Rio de Janeiro, v.46, n.04, p. 96-108, out./dez. 2006.

RICHARDSON, Roberto Jarry. Pesquisa social: métodos e técnicas. 3. ed., rev. e ampl. São Paulo: Atlas, 1999.

ROCHA, Angela da; SILVA, Jorge Ferreira da. Marketing de serviços: retrospectiva e tendências. Revista de Administração de Empresas - RAE. Rio de Janeiro, v.46, out./dez. 2006.

SAMARA, Beatriz Santos; BARROS, José Carlos de. Pesquisa de marketing: conceitos e metodologia. 3. ed. São Paulo: Pearson Education do Brasil, 2002.

VERGARA, Sylvia Constant. Métodos de pesquisa em administração. São Paulo: Atlas, 2005.

ZEITHAML, Valerie A.; BITNER, Mary Jo. Marketing de serviços: a empresa com foco no cliente. 2.ed. Porto Alegre: Bookman, 2003.

ZEITHAML, Valerie A.; PARASURAMAN, A. Service quality. United State of America: Marketing Science Institute, 2004. 